\title{
Cutaneous Horn of the Glans
}

\author{
Camilla Santos Ribeiro ${ }^{a}$ David Rubem Azulay ${ }^{a}$ \\ Danielle Carvalho Quintella ${ }^{b}$ Tullia Cuzzi ${ }^{b}$ Marcia Ramos-e-Silva ${ }^{a}$ \\ aSector of Dermatology and Post Graduation Course in Dermatology, University Hospital \\ and School of Medicine, Federal University of Rio de Janeiro, Rio de Janeiro, Brazil; \\ ${ }^{b}$ Department of Pathology, University Hospital and School of Medicine, Federal University \\ of Rio de Janeiro, Rio de Janeiro, Brazil
}

\section{Keywords}

Cutaneous horn $\cdot$ Verrucous carcinoma $\cdot$ Lichen sclerosis

\begin{abstract}
Cutaneous horn is a protuberance constituted by compact keratinous material, with a hard consistence similar to a horn, which occurs more frequently in photoexposed areas. The authors describe a case of cutaneous horn on the glans considered a rare location. Verrucous carcinoma was the histopathological diagnosis of the base of the horn and lichen sclerosis, the precursor lesion.
\end{abstract}

\section{Introduction}

Cutaneous horn is a morphologic designation for a protuberance constituted by compact keratinous material, with conic structure and hard consistence similar to a horn [1]. It is frequently associated to various pathological conditions as actinic keratosis, basal-cell carcinoma, squamous-cell carcinoma (SCC), seborrheic keratosis, verruca vulgaris, among others. It is usually asymptomatic but can become painful when traumatized or inflammed [2]. Middle age and elderly individuals are more affected [3], and it occurs with a greater frequency in photoexposed areas, as face, nose, external ears, forearms, and back of the hands [4].

Histopathology of the horn's base may present benign or malignant characteristics that must be differentiated so a proper surgical procedure should be performed with the histopathological evaluation of its base [3]. Malignant conditions are present in 16-20\% of the cases, and SCC is the most common malignant lesion. In horns located on the penile area, the probability of SCC increases up to 33\% [5]. 
With a little $>100$ reported cases in the literature, cutaneous horn on the glans is considered a rare occurrence. Since 1854, when the first case of cutaneous horn located on the penis was reported, conditions such as chronic irritation, phimosis, surgical trauma, and radiotherapy have been pointed out as possible risk factors for the horn formation [2].

Lichen sclerosus (LS) is a chronic disease, which can affect any area of the skin, although it is more common in an urogenital region. In men, it can involve the glans penis, prepuce, and urethra, leading to obstructive urinary symptoms, as the reported patient. It initiates as a depigmentation and may evolve to meatal urethral stenosis and even to involvement of the whole urethra, leading to great impairment of the urinary and sexual function. In this location, the more extensive cases are called obliterant xerotic balanitis. Urethroscopy and retrograde urethrography are efficient diagnostic methods for the internal involvement of the urethra [6].

The relationship between LS and SCC is well documented showing a very strong association [6-8]. LS should be considered a potential condition for malignant transformation, requiring regular consultations.

\section{Case Report}

Our patient is a 51-year-old man with a diagnosis of LS who returned to our Sector of Dermatology after 3 years without follow-up, complaining of intense pain in the penis and the appearance of a hardened lesion 4 months ago. He also referred having a posthectomy 6 years before with modification of the urinary discharge associated with thickened skin on the glans, all beginning after the procedure. The examination showed a $4 \mathrm{~cm}$ cutaneous horn on an erythematous and infiltrated base and some areas of hypochromia and keratosis on the glans (Fig. 1).

After a joint decision with the Service of Urology, the patient was submitted to excision of the horn (Fig. 2), external meatotomy, and puncture cystostomy. Histopathological examination (Fig. 3-5) revealed prominent squamous proliferation with hyperkeratosis, parakeratosis, acanthosis, and papillomatosis. Large and irregular rete pegs with a bulbous appearance, composed of large and well-differentiated keratinocytes, represented the lower part of the lesion. Adjacent to the lesion a hyalinized stroma beneath the epidermis with mild hyperkeratosis and moderate and irregular acanthosis were present. These findings are compatible with LS. The search for HPV through polymerase chain reaction was negative.

The patient relinquished treatment and returned only 9 months after the procedure, complaining of worsening of the modification of the urinary discharge. Urethrocistography showed extensive area of bulb-membranous urethra. A partial penectomy, urethrectomy, and perineal urethrostomy were performed (Fig. 6). The patient evolved with urethral stenosis and recurrent urinary infections, expected repercussions for this current condition, and he was submitted to regular urethral dilation.

\section{Discussion}

A study with 130 men showed an evolution period of 14-30 years between the onset of LS and the development of penial carcinoma [9]. The reported case showed a time frame of 3 years between the diagnosis of LS and the appearance of the SCC.

Verrucous carcinoma is a well-differentiated variant of SCC, which can be located on skin and mucosa. It grows slowly in a more expansive than infiltrative pattern [10]. Its 
Fig. 1. Cutaneous horn with $4 \mathrm{~cm}$ in an erythematous and infiltrated base and some areas of hypochromia and keratosis in the glans.
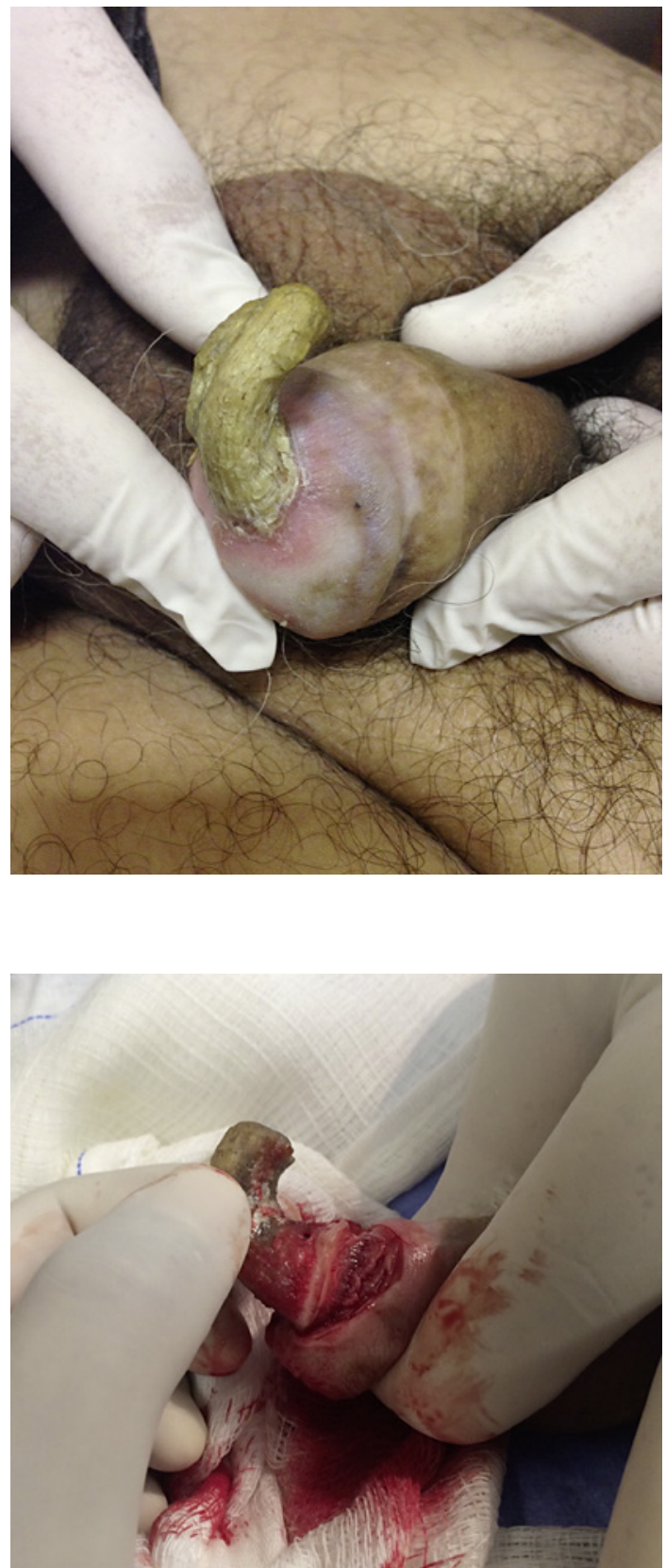

Fig. 2. Excision of the cutaneous horn.

etiopathogeny, although not very well understood, may have relationship with HPV, smoking, and chronic inflammation $[8,10]$.

This malignant tumor is also known as papillomatous cutaneous carcinoma and has several other different designations, related to the involved location: in the genital region, it is called tumor of Buschke-Lowenstein; on the soles, carcinoma cuniculatum; and in the oral cavity, papillomatous oral florid or tumor of Ackerman [10].

Some factors have been associated because of their presence in both verrucous carcinoma and LS; among them: phymosis, recuring balanopostitis, poor hygiene, HPV infection, and diabetes mellitus. Gutiérrez-Pascual et al. listed 29 cases of anogenital verrucous carcinoma associated to LS described in the literature. From these only 4 were submitted to HPV screening, 2 showing positive result [8]. 
Fig. 3. Down growth of squamous epithelium with blunted borders, without significant atypia (objX10).

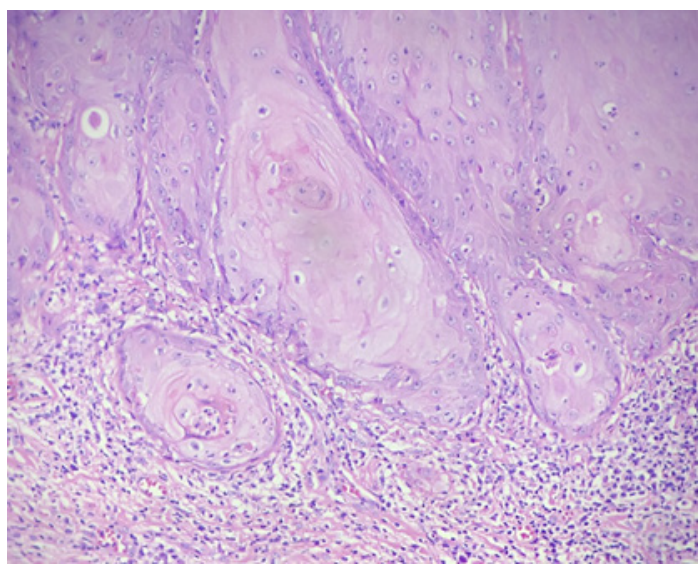

Fig. 4. Slightly acanthotic epidermis over enlarged papillary dermis with homogenization of collagen and some inflammatory cells (objX10).

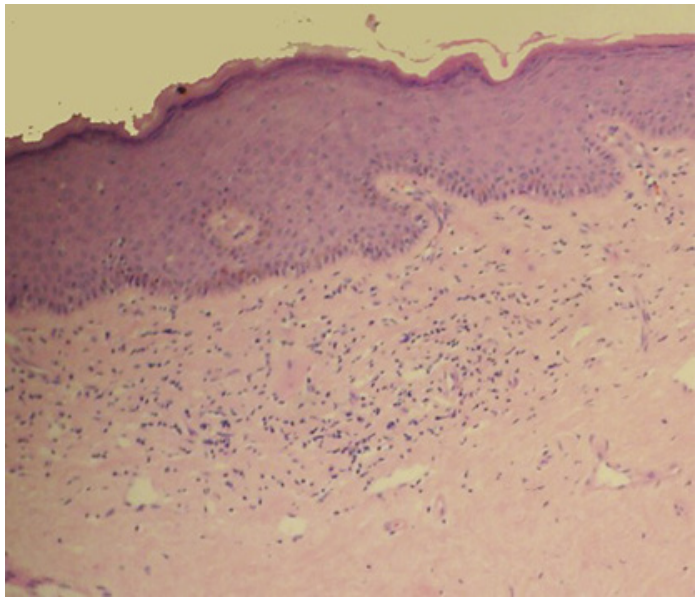

Fig. 5. Absence of elastic fibers (Orcein stain, objX10).

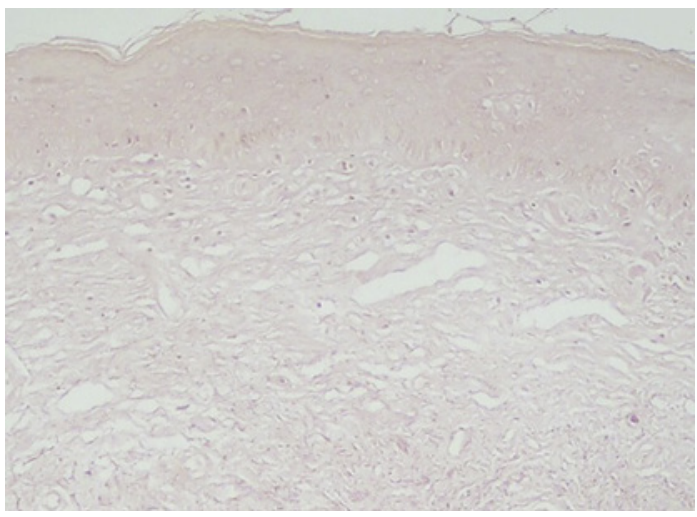

\section{Conclusions}

In the present case report, glans LS was considered the precipitating factor for the development of cutaneous horn and for the transformation into verrucous carcinoma. The management in a cutaneous horn should always include a biopsy for histopathological study of the base of the lesion in order to elucidate the subjacent disease, either benign or malignant. 
Fig. 6. Partial penectomy.

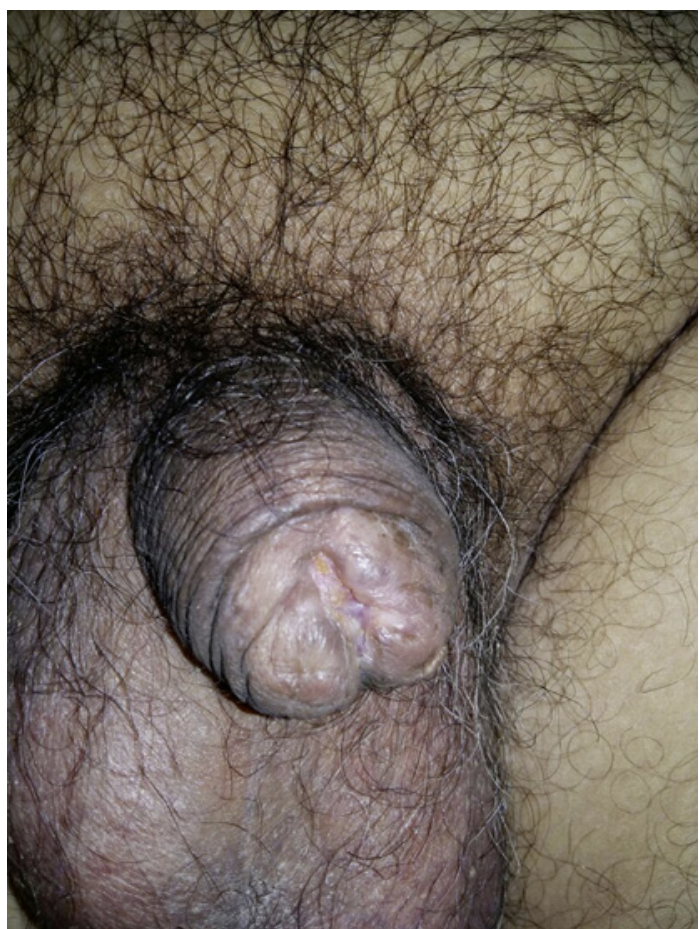

Patients with LS must always be regularly observed due to its potential to malignant transformation.

\section{Statement of Ethics}

The authors have complied with the guidelines for human studies and all the authors were ethically conducted in accordance with the World Medical Association Declaration of Helsinki. The patient has given his written informed consent for publication of this case report and the accompanying images. This is not a research and the Committee for Ethics in Research of our University Hospital exempts case reports from Ethical Committee approval.

\section{Conflict of Interest Statement}

The authors have no conflicts of interest to declare.

\section{Funding Resources}

There was no funding for this investigation.

\section{Author Contributions}

Dr. Camilla Santos Ribeiro, MD: substantial contributions to the acquisition, analysis, or interpretation of data for the work. Drafting the work. Final approval of the version to be published. Prof. David Rubem Azulay, MD, PhD: substantial contributions to the acquisition, 
analysis, or interpretation of data for the work. Drafting the work. Final approval of the version to be published. Prof. Danielle Carvalho Quintella, MD, MSc: substantial contributions to the acquisition, analysis, or interpretation of data for the work. Revising the article critically for important intellectual content. Final approval of the version to be published. Prof. Tullia Cuzzi, MD, PhD: substantial contributions to the acquisition, analysis, or interpretation of data for the work. Revising the article critically for important intellectual content. Final approval of the version to be published. Prof. Marcia Ramos-e-Silva, MD, PhD: substantial contributions to the acquisition, analysis, or interpretation of data for the work. Revising the article critically for important intellectual content. Final approval of the version to be published.

\section{References}

1 Gupta V, Chopra V, Verma S. A large cutaneous horn of the glans penis: a rare presentation. Indian J Surg. 2014; 76(2):143-4.

2 Karthikeyan K. Penile cutaneous horn: an enigma - newer insights and perspectives. Indian J Sex Transm Dis. 2015;36(1):26-9.

3 Mantese SA, Diogo PM, Rocha A, Berbert AL, Ferreira AK, Ferreira TC. Cutaneous horn: a retrospective histopathological study of 222 cases. An Bras Dermatol. 2010;85(2):157-63.

4 Kutlubay Z, Engin B, Zara T, Tüzün Y. Anogenital malignancies and premalignancies: facts and controversies. Clin Dermatol. 2013;31(4):362-73.

5 Tauro LF, Martis JJ, John S, Kumar KP. Cornu cutaneum at an unusual site. Indian J Plast Surg. 2006;39(1):76-8.

6 Pugliese JM, Morey AF, Peterson AC. Lichen sclerosus: review of the literature and current recommendations for management. J Urol. 2007;178(6):2268-76.

7 Wang SH, Chi CC, Wong YW, Salim A, Manek S, Wojnarowska F. Genital verrucous carcinoma is associated with lichen sclerosus: a retrospective study and review of the literature. J Eur Acad Dermatol Venereol. 2010;24(7): 815-9.

8 Gutiérrez-Pascual M, Vicente-Martín FJ, López-Estebaranz JL. [Lichen sclerosus and squamous cell carcinoma]. Actas Dermosifiliogr. 2012;103(1):21-8.

9 Barbagli G, Palminteri E, Mirri F, Guazzoni G, Turini D, Lazzeri M. Penile carcinoma in patients with genital lichen sclerosus: a multicenter survey. J Urol. 2006;175(4):1359-63.

10 Zanini M, Wulkan C, Paschoal FM, Maciel MH, Machado-Filho C. Verrucous carcinoma: a clinical-histopathologic variant of squamous cell carcinoma. An Bras Dermatol. 2004;79(5):619-21.

\section{Karger'}

